\title{
PROBLEMÁTICA AMBIENTAL DEL RÍO MANZANARES Y LA ZONA COSTERA DE CUMANÁ
}

William Senior, Julián Castañeda y Gregorio Martínez

Departamento de Oceanografía, Instituto Oceanográfico de Venezuela, Universidad de Oriente. 


\section{INTRODUCCIÓN}

El río Manzanares con sus afluentes constituye una cuenca aislada, perteneciente a la gran cuenca del Caribe (figura 1). Nace en el cerro Turimiqire a una altura superior a $2000 \mathrm{~m}$ sobre el nivel del mar y desemboca en la entrada del Golfo de Cariaco, ejerciendo una gran influencia hacia el lado occidental de la costa de Cumaná, la cual se encuentra ubicada entre los $64^{\circ} 24^{\prime}$ latitud Norte, $64^{\circ}$ $10^{\prime}$ longitud Oeste y los $10^{\circ} 30^{\prime}$ latitud Norte y $64^{\circ} 20^{\prime}$ longitud Oeste. Su hoya hidrógrafica cubre una extensión aproximada de 165.210 hectáreas.

Este cuerpo fluvial de gran importancia en la región Nor-Oriental del país, recibe por su margen derecho 9 ríos, 13 riachuelos y quebradas y por el izquierdo 14 ríos principales y 6 secundarios (Senior, 1994). El aporte anual de su escorrentia se estima en 600 millones de $\mathrm{m}^{3}$, la cual se reparte entre la zona del aliviadero, sector donde se produce una gran sedimentación y su desembocadura original, pero en los últimos años (1980-1991), se ha incrementado en más de un 20\% (770.689 x $10^{6}$ m³; (Aguilera,1976; Alvarado, 1976; Senior, 1994; León 1995 ).

Las descargas del río Manzanares, originan una pluma laminar cuyos límites forman un sistema frental. Primordialmente el eje principal de la pluma se orienta hacia el Sur Oeste como consecuencia del la intensidad de los vientos alisios predominantes, sin emabargo en ocasiones durante los períodos prolongados de calma la pluma esta sometida a las fuerzas inerciales producto de la rotación de la tierra. Como resultado, se observa que el eje principal de la pluma se orienta en la dirección Este, penetrando el Golfo de Cariaco.

Desde el Distrito Montes, en Cumanacoa el Manzanaaaares acoge de efluentes de las descargas de desechos químicos del central azucarero y de las aguas domésticas de la región que son vertidas 
al río Guasdua - afluente del Manzanares-. Por otra parte, en su cuenca alta es frecuente la práctica de talas y quemas indiscriminadas con fines agrícolas. Actividades inadecuadas que causan erosión y disminución progresiva del caudal del río en épocas de sequía (Senior, 1994; León., 1995).

En las adyacencias de su desembocadura, el Manzanares se encuentran ubicadas una serie de industria y servicios que imponen un fuerte estrés sobre el ecosistema. Asi por ejemplo, se evidencian las descargas líquidas industriales de una procesadora de pescado y los desechos sólidos y líquidos del Mercado Municipal; de igual manera se encuentran una estación de servicios, un astillero naval y una planta de hielo. Esta última utiliza amoniaco durante el proceso de refrigeración. En último término en sus márgenes se encuentran estructuras habitacionales del tipo rancho, que son usadas por un sector humilde de la población en condiciones muy deplorables de insalubridad. Todos los actores arriba mencionados constituyen potenciales fuentes de metales pesados cuyo destino son las aguas del río.

Estudios recientes ponen en evidencia una alteración de la calidad de las aguas de este río en su cuenca baja desde Cumanacoa hasta su desembocadura, como consecuencia del desarrollo de las actividades industriales y agrícolas. Ello genera un progresivo aumento en los niveles de materia orgánica, organismos coliformes y metales pesados en las aguas costeras de Cumaná (Senior y Godoy, 1991; labichella, 1993; León, 1995), hecho que pone de manifiesto la necesidad de un monitoreo continuo de sus aguas (Senior y Godoy, 1991; Senior, 1994; León, 1995). 


\section{ESTACIONES DE MUESTREO}

Se colectaron un total de quince (15) muestras superficiales de agua del río Manzanares y sus afluentes principales, desde el sector conocido como Las Trincheras, en la población de Cumanacoa, hasta la desembocadura en la entrada del Golfo de Cariaco (fig. 1).

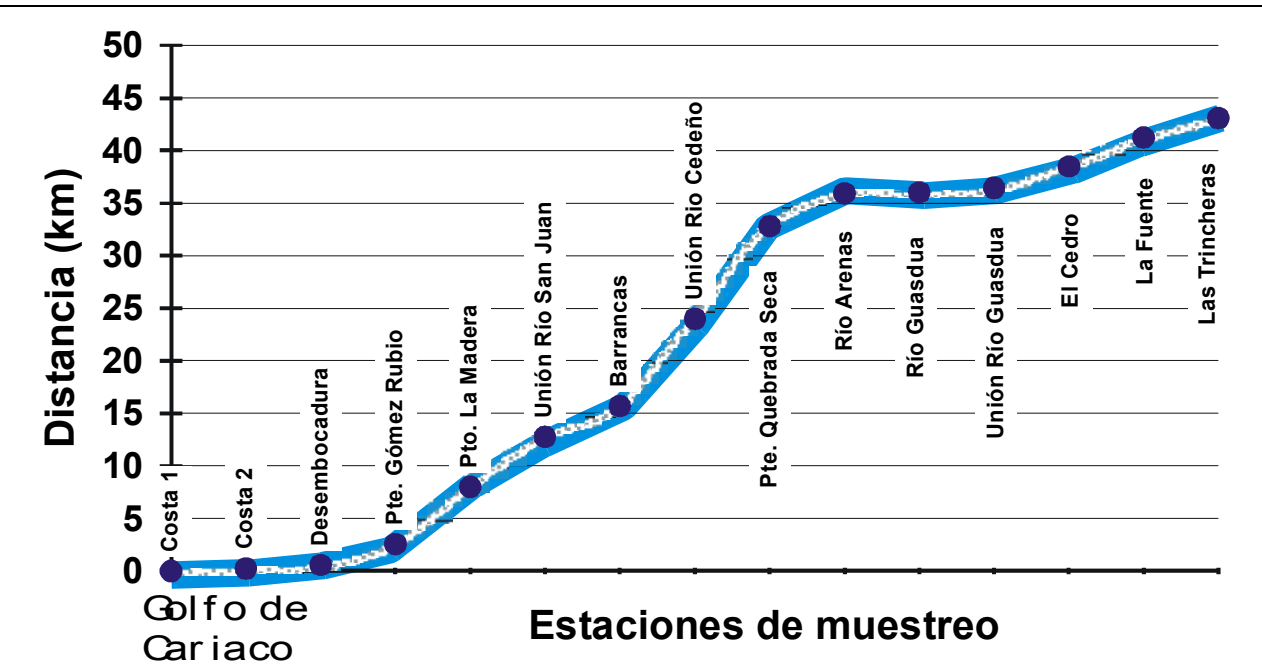

Fig. 1.- Ubicación relativa de las estaciones de muestreo, tomando como referencia su distancia a la costa de Cumaná.

\section{RESULTADOS}

\section{TEMPERATURA}

Las temperaturas registradas en el río estuvieron comprendidas entre $22^{\circ} \mathrm{C}$ y $26,6^{\circ} \mathrm{C}$ (fig. 2). Las más bajas temperaturas se registraron hacia el sector montañoso de La fuente y Las Trincheras, a una distancia superior a $45^{\circ} \mathrm{km}$ de la desembocadura. La temperatura se incrementa progresivamente hasta alcanzar sus valor máximo en la desembocadura del río. Es notorio el aporte de aguas cálidas del Guasduas $\left(35 \mathrm{~km} ; 24 \cdot 1^{\circ} \mathrm{C}\right)$. 


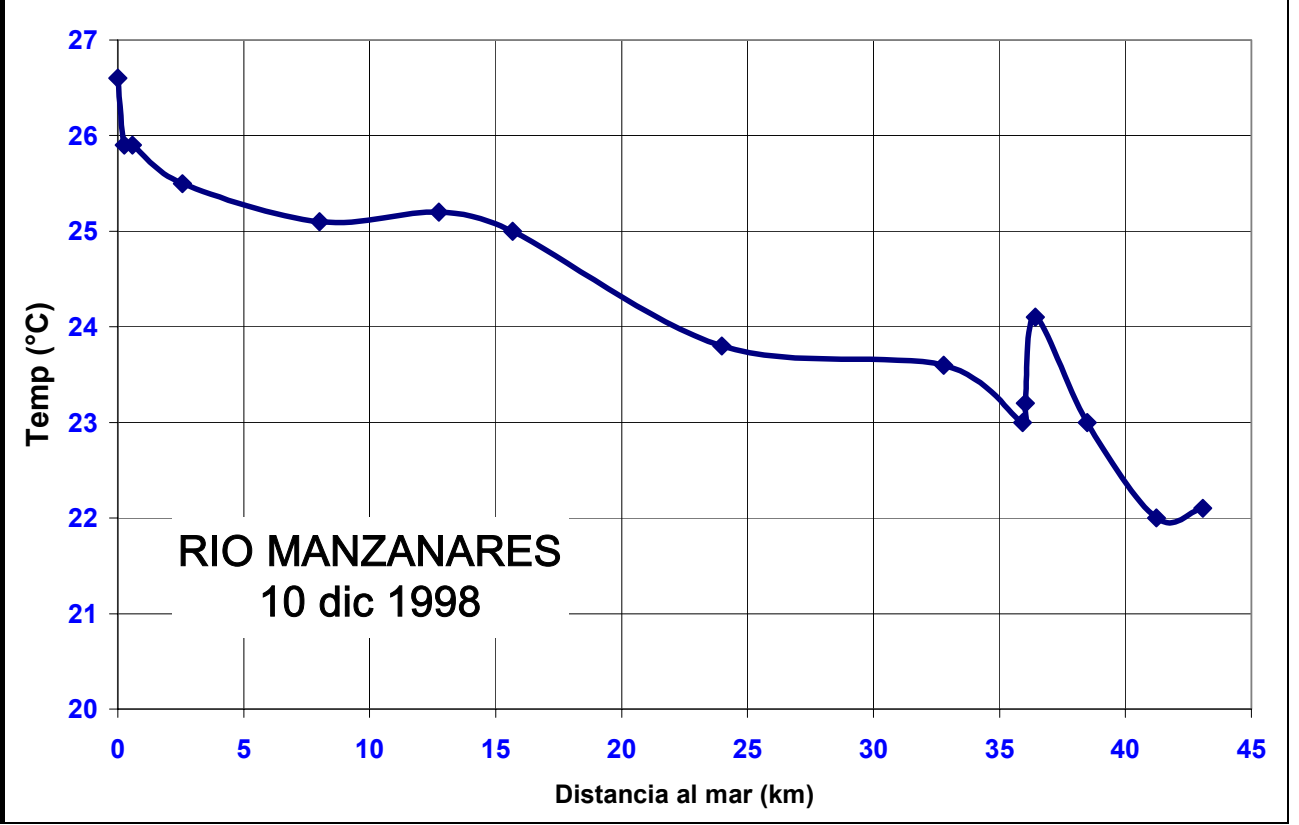

Fig. 2.- Temperaturas a lo largo del Río Manzanares, ascendiendo desde la desembocadura.

La temperatura en el río Manzanares está dominada por ciclos estacionales. Ellas están asociadas a las fluctuaciones periódicas de la intensidad de radiación solar y al caudal del Manzanares, como consecuencia de las precipitaciones en su cuenca alta. De manera general, las temperaturas del río, en su cuenca baja, son inferiores a $26{ }^{\circ} \mathrm{C}$, durante el período noviembre - febrero; mientras que entre el período marzo - junio las temperaturas son superiores a $27{ }^{\circ} \mathrm{C}$ (Senior y Godoy, 1990; Godoy, 1991; León Luna, 1995; Marques, 1997).

\section{Ph}

El río muestra valores de $\mathrm{pH}$ variables a lo largo de su curso de agua (fig. 3).

Los valores de $\mathrm{pH}$ estuvieron comprendidos entre 6,8 y 8,41 unidades. Es interesante observar la disminución del pH en las cercanías del kilómetro 35, ocasionado por las aguas del río Guasdua. Las variaciones irregulares continúan hacia la desembocadura registrándose un mínimo marcado 
cerca del kilómetro 1. Esta última disminución del pH es ocasionada por las descargas de desechos domésticos en ese sector del ecosistema.

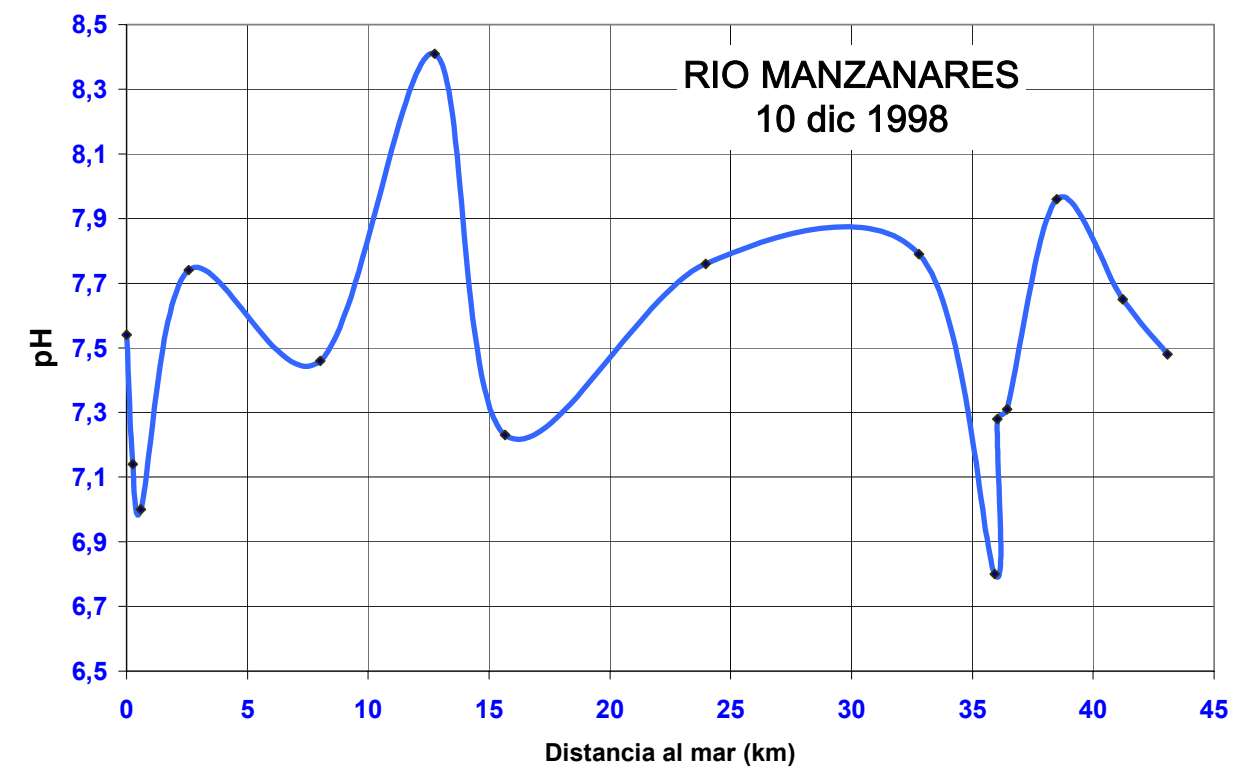

Fig. 3.- Variación longitudinal del pH en el Río Manzanares, durante el mes de diciembre de 1998.

\section{OXIGENO DISUELTO}

La variación longitdinal del oxígeno disuelto (fig. 4) pone de manifiesto la carga contaminante vertida al Manzanares por el río Guasdua. En este sector de unión de los dos ríos las concentraciones caen de 8,60 mg/l a 5,56 mg/l. Luego de reponerse los niveles de oxígeno en las aguas, el contenido de oxígeno se mantiene estable en todo el curso de agua, hasta llegar a la desembocadura donde las concentraciones disminuyen hasta 4,59 mg/l. Esta disminución se atribuye a la menor solubilidad de este gas en las aguas saladas, y a los aportes importantes de materia orgánica que existen en este sector del río, proveniente de los desechos urbanos e industriales de la ciudad de Cumaná. 


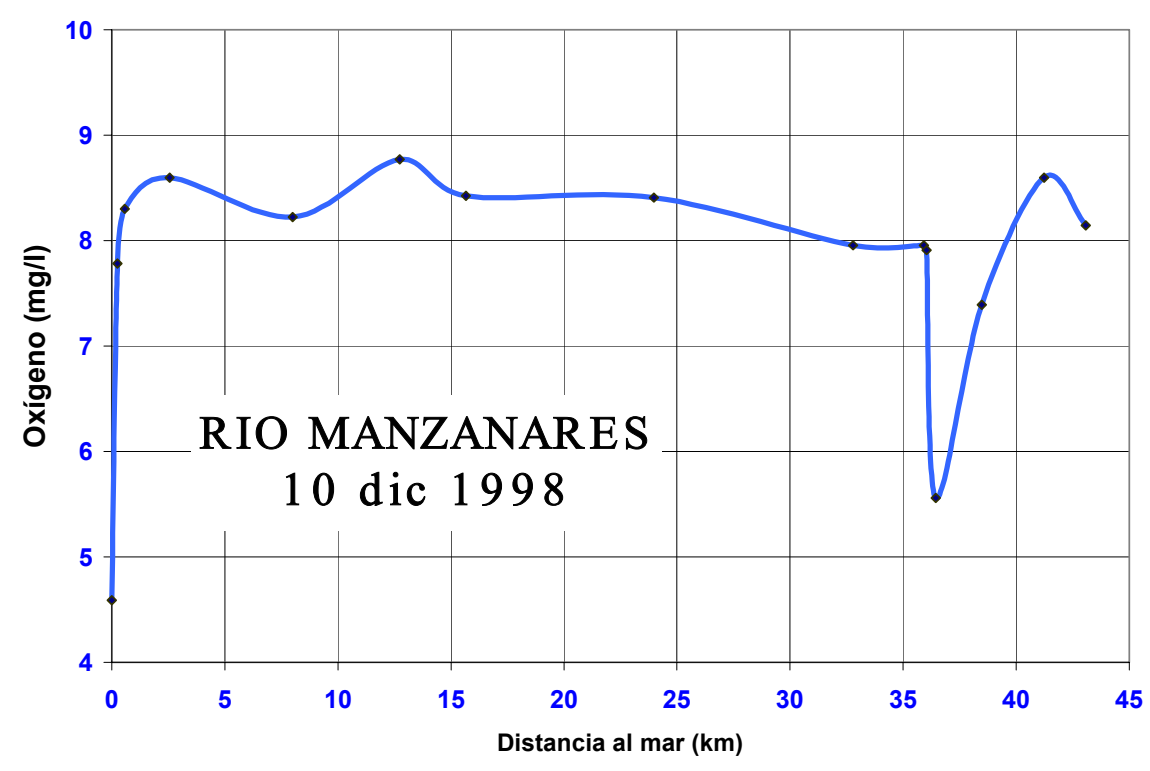

Fig. 4.- Variación longitudinal del Oxígeno disuelto en el Río Manzanares, durante el mes de diciembre de 1998.

A pesar de la carga orgánica que arrastra y que es vertida al río, las aguas superficiales mantienen altas concentraciones de oxígeno.

\section{COMPUESTOS NITROGENADOS}

En la figura 5 se presenta la evolución, a lo largo del río de los compuestos nitrogenados. Gran parte del nitrógeno arrastrado por el río está bajo la forma de materia orgánica. Las concentraciones de nitrógeno total encontradas oscilaron entre $27,30 \mu \mathrm{mol} / / \mathrm{l}$ y $58,10 \mu \mathrm{mol} / \mathrm{l}$. Se puede apreciar un aporte al río Manzanares de compuestos nitrogenados por el río Guasdua, siendo en este sitio donde se detectaron los valores extremos. Las concentraciones alcanzan su nivel mínimo en el kilómetro 24, donde las aguas del río Cedeño se unen a las aguas del río Manzanares. La disminución de las concentraciones sugiere que la carga de elementos nitrogenados del río Cedeño 
es menor a la arrastrada por el Manzanares. Las concentraciones se mantienen con muy pocas variaciones entre los kilómetros 15 y 2,5 para luego disminuir en la desembocadura, como consecuencia de la mezcla de las aguas del río con las aguas marinas, de bajo contenido en estos elementos.

El nitrógeno inorgánico arrastrado por el río se encuentra prácticamente bajo la forma de nitrato, lo cual es indicativo de que estamos en presencia de una materia orgánica en avanzado estado de descomposición. Las concentraciones de nitrato estuvieron comprendidas entre 2,48 $\mu \mathrm{mol} /$ y 33,30 $\mu \mathrm{g} / \mathrm{l}$. La evolución, a lo largo del río, de estos compuestos fue paralela a la del nitrógeno total.

Las concentraciones de amonio estuvieron entre $0,1 \mu \mathrm{mol} / /$ y $4,0 \mu \mathrm{mol} / /$, con un comportamiento similar al de los otros compuestos nitrogenados.

Las concentraciones de elementos nitrogenado en el Manzanares están íntimamente relacionadas con el gasto del río (Senior y Godoy, 1990; Godoy, 1991). Estos autores señalan que las concentraciones de nitrato, en la cuenca baja, son del orden de 6 a $20 \mu \mathrm{mol} / \mathrm{l}$, y reflejan la influencia agrícola de la cuenca drenada. Godoy (1991) estimó el aporte de nitrato a la zona costera en 137 ton/año, reflejando un incremento con relación a lo estimado por Alvarado (1976), quien realizó estimaciones de 102 ton/año. Es casi seguro que el aporte de nitrato se ha incrementado en los últimos años, como consecuencia del incremento del desarrollo agrícola en los últimos años. 


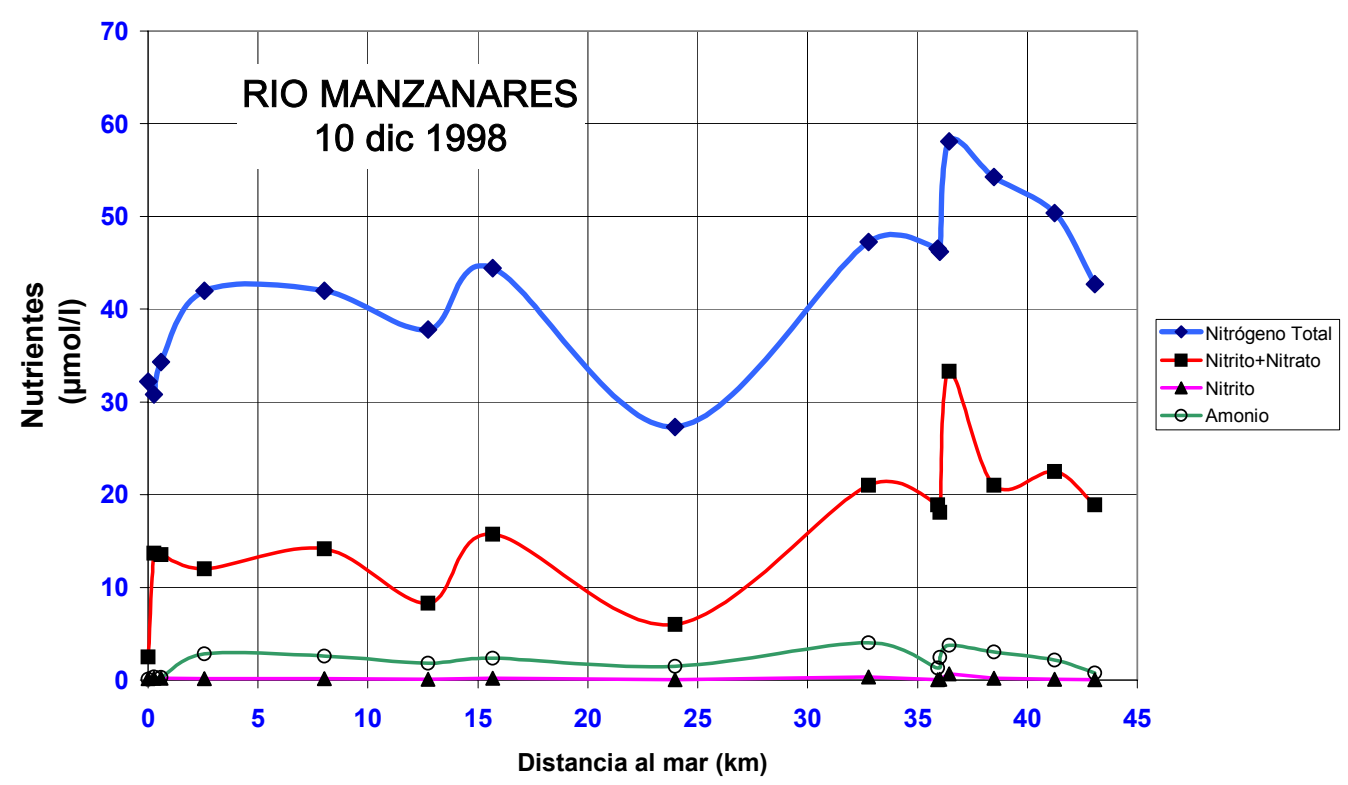

Fig. 5.- Variación longitudinal de los elementos nutritivos en el Río Manzanares, diciembre de 1998.

Godoy (1991) reporta concentraciones de nitrógeno total variando entre $30 \mu \mathrm{mol} / /$ y $540 \mu \mathrm{mol} / \mathrm{l}$, durante un período de observaciones de 12 meses, en los últimos tres kilómetros antes de la desembocadura del río en el mar. Las concentraciones de estos elementos están íntimamente relacionadas con el ciclo hidrológico de la región, alcanzándose las concentraciones máximas durante los períodos de mayor caudal del río,

\section{COMPUESTOS DE FOSFORO}

La variación longitudinal de los compuestos de fósforo (fósforo total y fosfato) en el Manzanres se presenta en la figura 6 . Las concentraciones de fósforo total variaron entre $0,19 \mu \mathrm{mol} / / \mathrm{y}$ $5,16 \mu \mathrm{mol} / /$; mientras que las concentraciones de fosfatos estuvieron comprendidas entre $0,13 \mu \mathrm{mol} / \mathrm{l}$ y $4,23 \mu \mathrm{mol} / \mathrm{l}$. Estos compuestos se comportan de forma paralela. Las concentraciones más elevadas son ocasionadas por el aporte del río Guasdua al Manzanares. Gran parte de este aporte se efectúa bajo la forma de fosfato, presumiblemente proveniente de la utilización de fertilizantes en la zona. Un máximo secundario se aprecia a nivel de la estación de Quebrada Seca. 
En este punto los compuestos orgánicos fueron predominantes sobre los inorgánicos, lo cual sugiere que se trata de aportes de origen doméstico. Las concentraciones alcanzan los valores mínimos en el kilómetro 24, donde el río Cedeño se une al Manzanares. En este punto casi todo el fósforo se encuentra bajo la forma inorgánica (fosfato). El aporte de fósforo al Manzanares por las aguas del río Cedeño es insignificante. A partir de este punto las concentraciones aumentan por el predominio del Manzanares sobre sus afluentes.

En el sector de Puerto de La Madera existe un aporte de fósforo, principalmente bajo la forma orgánica, el cual es originado por el vertido de aguas usadas de las poblaciones. Desde este punto hasta la desembocadura el fósforo se encuentra predominantemente bajo la forma de fósforo orgánico, poniendo de manifiesto las descargas de aguas usadas que recibe el Manzanares en el tramo final de su cauce. La disminución de las concentraciones en el kilómetro 0 es provocada por la mezcla de las aguas dulces con las aguas marinas.

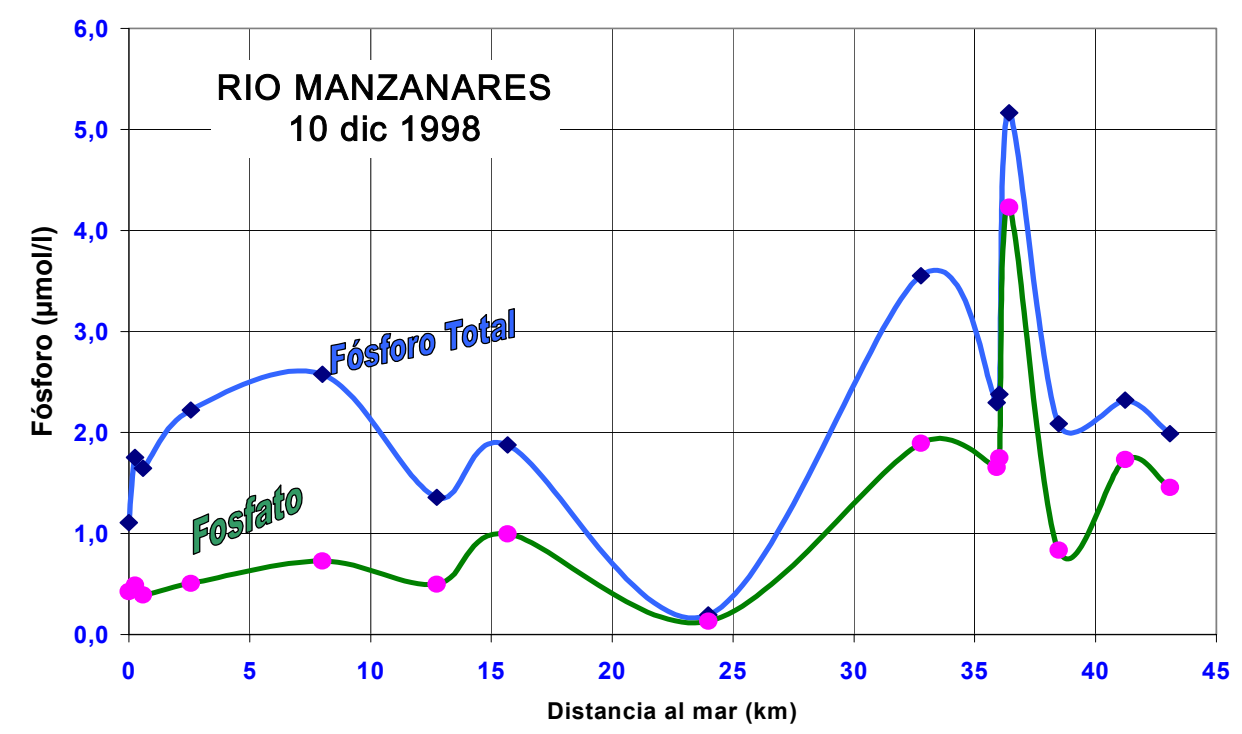

Fig. 6.- Variación longitudinal de los compuestos de fósforo en el Río Manzanares, diciembre de 1999.

\section{SILICATOS}

Las concentraciones de silicato se mantienen prácticamente constantes entre el kilómetro 45 y el 15. Los valores característicos son del orden de $145 \mu \mathrm{mol} / \mathrm{l}$. Las concentraciones disminuyen 
bruscamente en el sector de Puerto de La madera, donde se registraron concentraciones de 40,3 $\mu \mathrm{mol} / \mathrm{l}$. Esta disminución de la concentraciones se encuentra asociada al incremento de las concentraciones de fósforo total, y a una disminución del pH, lo cual es indicativo de la existencia de un aporte de aguas servidas en el sector. Las concentraciones se incrementan inmediatamente después a sus valores normales, para luego disminuir como consecuencia de la mezcla entre las aguas dulces y las aguas marinas.

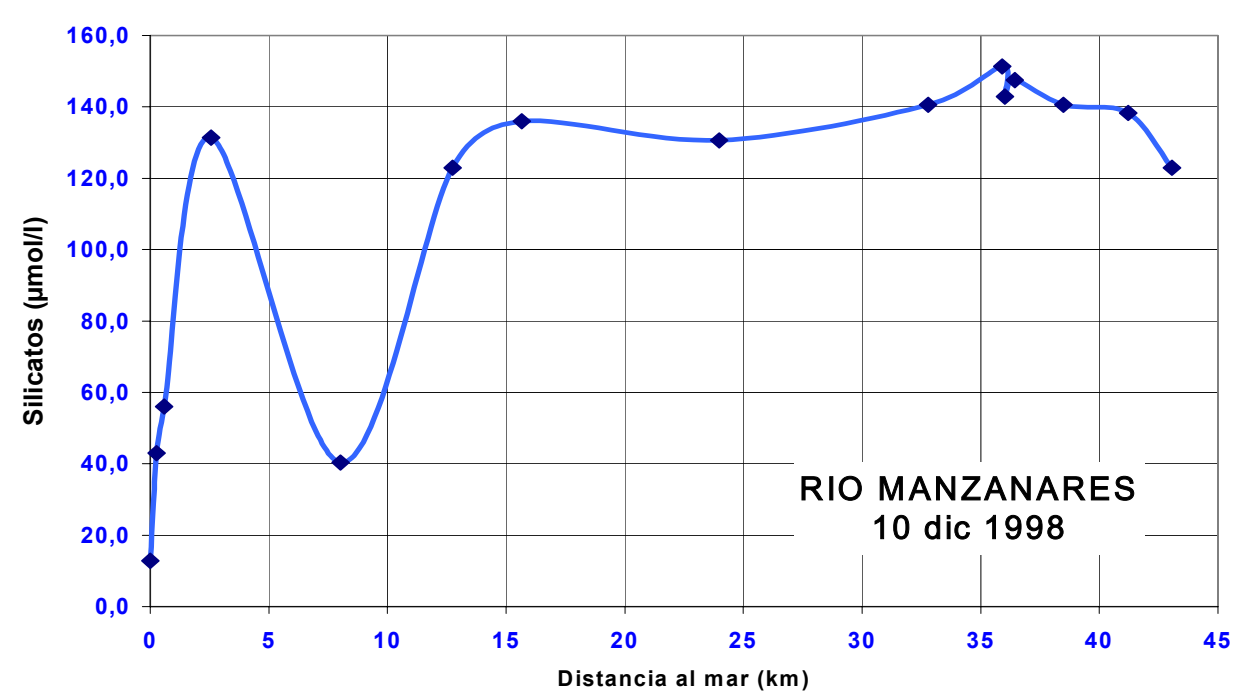

Fig. 7.- Variación longitudinal de los silicatos en el Río Manzanares, diciembre de 1999.

\section{CALIDAD DE LAS AGUAS}

\section{DEMANDA BIOQUIMICA DE OXIGENO $\left(\mathrm{DBO}_{5}\right)$}

En la figura 8 se presenta la variación longitudinal de la Demanda Bioquímica de Oxígeno del río Manzanares. Las concentraciones de $\mathrm{DBO}_{5}$ estuvieron comprendidas entre 3 y $22,5 \mathrm{mg} / \mathrm{l}$. Entre los kilómetros 25 y 45 las concentraciones de $\mathrm{DBO}_{5}$ son superiores a $15 \mathrm{mg} / \mathrm{l}$, y son indicativas de la carga orgánica que arrastra este curso de agua. Se apreció una disminución de la $\mathrm{DBO}_{5}$ en la unión 
del río Guasdua con el Manzanares, lo que está sugiriendo que el Guasdua aporta una carga orgánica difícilmente degradable. En efecto, el Guasdua recibe desechos provenientes del Central Azucarero de Cumanacoa, desechos ellos difícilmente degradables.

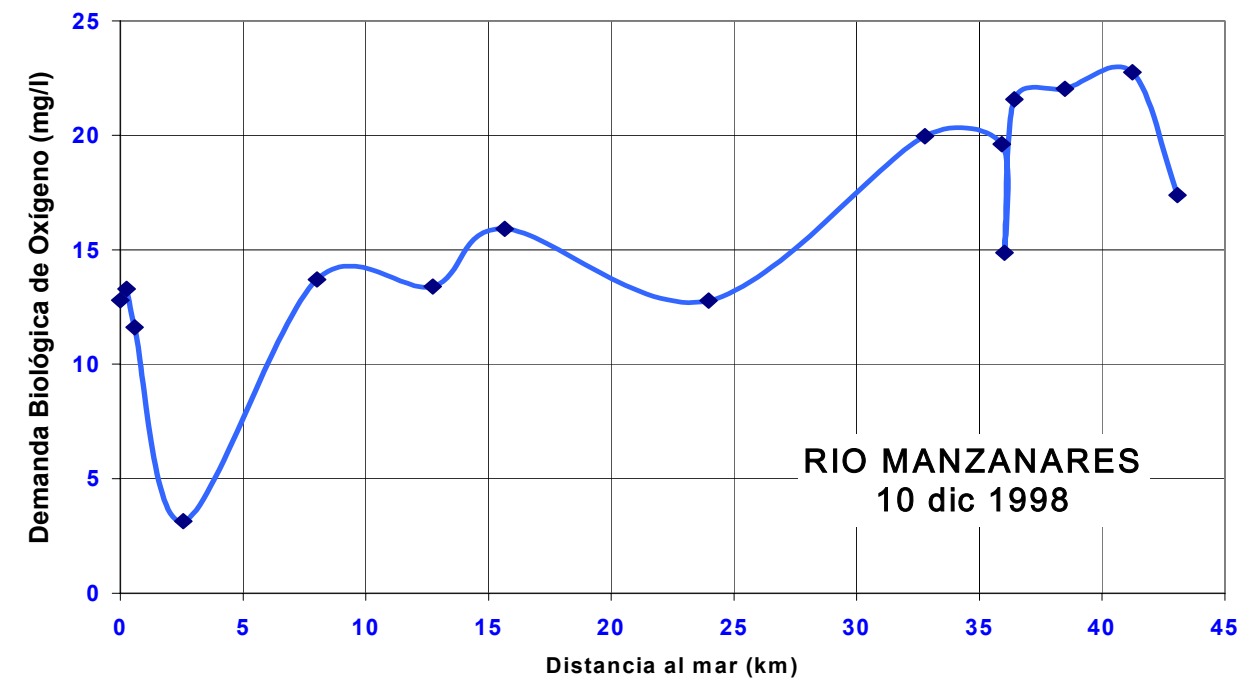

fig. 8.- Variación longitudinal de la demanda bioquímica de oxígeno ((BBO5)en el Río Manzanares, diciembre de 1999.

\section{DEMANDA QUIMICA DE OXIGENO (DQO)}

La Demanda Química de Oxígeno presentó concentraciones que oscilaron entre $21 \mathrm{mg} / \mathrm{l}$ y $214 \mathrm{mg} / \mathrm{l}$ (fig. 9). Entre los kilómetros 7 y 45 las concentraciones de DQO exceden los $50 \mathrm{mg} / \mathrm{l}$. Este resultado refleja el alto contenido de materia orgánica difícilmente degradable que arrastra el Manzanares. Es de resaltar, en primer lugar el aumento de las concentraciones en la confluencia de los ríos Guasdua y Manzanares. Este resultado viene a confirmar lo descrito en el caso de la DBO5, en cuanto al aporte de una materia orgánica difícilmente degradable. Las concentraciones se incrementan abruptamente en el kilómetro 16, en el sector conocido como Barrancas. Allí fueron registrados los valores máximos, y se trata del vertido de un material de difícil degradación. Este incremento de las concentraciones se acompaña de un aumento de los valores de los compuestos de fósforo y nitrógeno, así como de una disminución del $\mathrm{pH}$. A partir de este punto las concentraciones disminuyen, para alcanzar el valor mínimo en el kilómetro 2,5. El aumento que se 
apreció posteriormente es consecuencia del vertido en la zona de la desembocadura del Manzanares de cargas contaminantes, tanto domésticas como industriales.

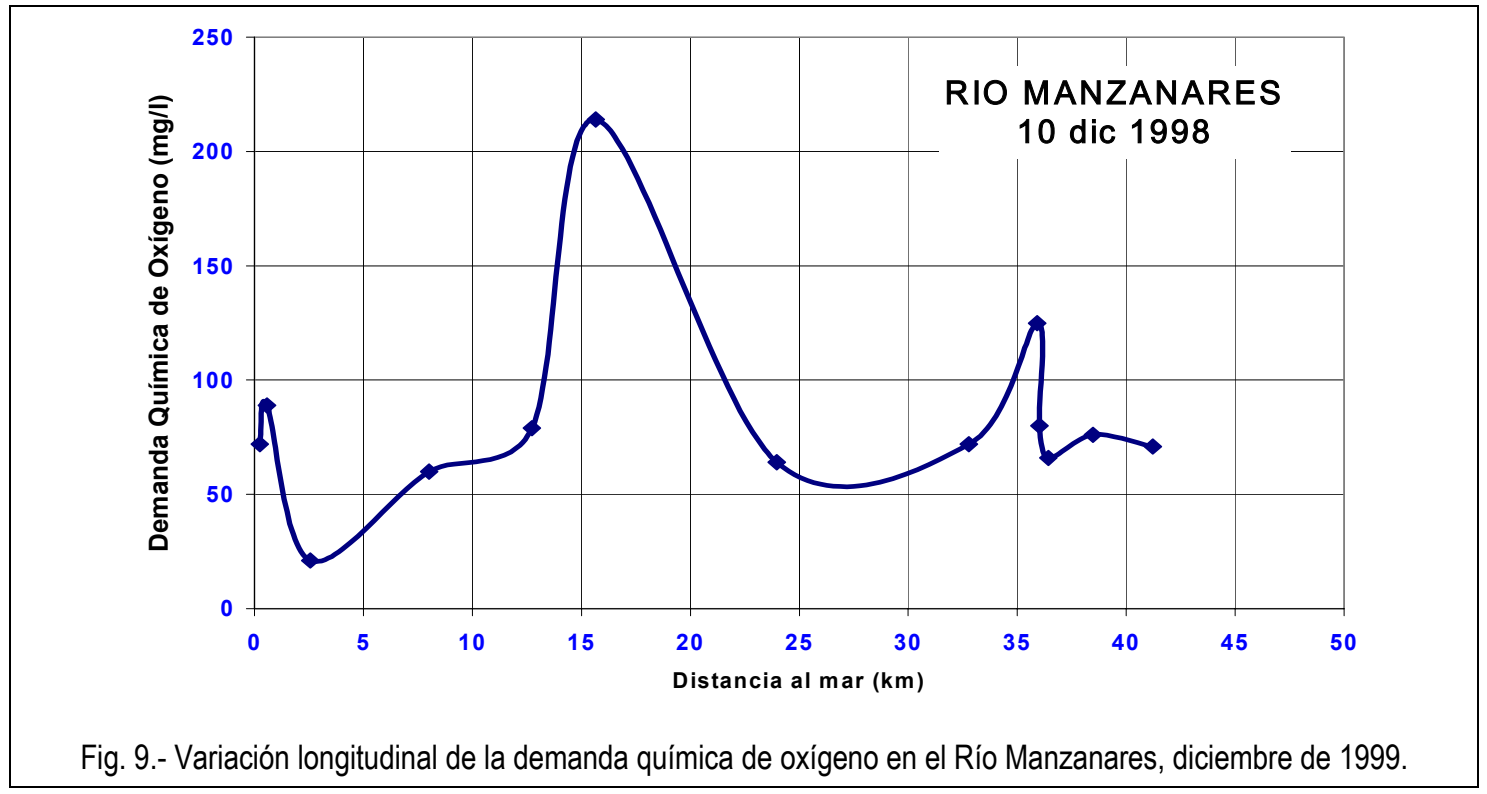

\section{ORGANISMOS COLIFORMES}

Las concentraciones de organismos coliformes se presenta en la figura 10. Las concentraciones de coliformes, tanto totales como fecales se mantuvieron por encima de los 1.000 organismos por cada $100 \mathrm{ml}$ de muestra. Este resultado indica el grado de contaminación bacteriana que presenta el río Manzanares y sus afluentes. La Legislación venezolana establece concentraciones inferiores a $1.000 \mathrm{NMP} / 100 \mathrm{ml}$ coliformes totales y de $200 \mathrm{NMP} / 100 \mathrm{ml}$ coliformes fecales como concentraciones límites para las aguas destinadas al contacto humano total, valores ampliamente superados por las aguas del Manzanares. Las mayores concentraciones de organismos coliformes se detectaron en el sector El Cedro, donde alcanzaron valores de $46 \times 10^{7} \mathrm{NMP} / 100 \mathrm{ml}$, en el caso de los totales, y $53 \mathrm{x}$ $10^{4} \mathrm{NMP} / 100 \mathrm{ml}$, en el caso de los fecales. Ahora bien, en el sector los Cedros se encuentra ubicado uno de los balnearios más visitados por los pobladores de la región. Las altas cargas bacterianas de las aguas que usan los desprevenidos bañistas deben ser motivo de para que las 
autoridades de gobierno tomen obligadas medidas sanitarias, con la finalidad de prevenir posibles epidemias.

Las aguas del río Guasdua aportan concentraciones de coliformes por encima de las normas establecidas, pero en menor concentración a las existentes en el Manzanares.

La afluencia de los ríos Cedeño y San Juan ocasionan una disminución de las concentraciones de organismos coliformes. En el tramo final del Manzanares, antes de su desembocadura al mar, recibe importantes aportes de estos organismos, como consecuencia del vertido de las aguas servidas de las barriadas de la ciudad de Cumaná, mercado municipal, empresas y servicios afiens con el procesamiento y venta de pescado.

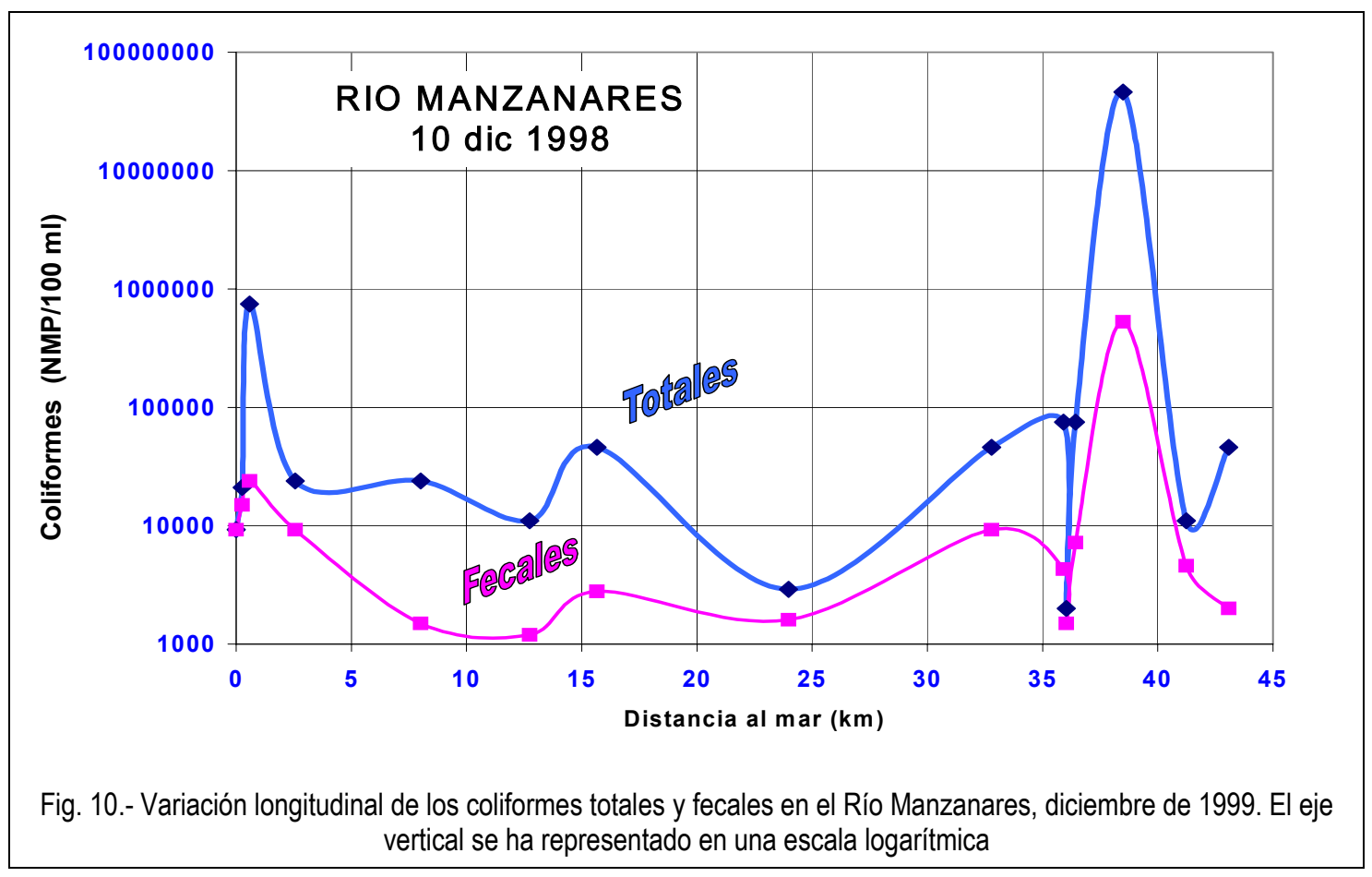

Fernández (1984) señala la presencia de organismos coliformes a niveles de $10^{5}$ a $10^{8} \mathrm{NMP} / 100 \mathrm{ml}$, durante el período comprendido entre 1971 y 1980, y los asociaba a la descarga de aguas servidas de las poblaciones asentadas en la ribera del manzanares, desde Cumanacoa hasta la 
desembocadura. De igual manera, Godoy (1991), durante observaciones realizadas entre 1988 y 1989 reporta una elevada contaminación fecal del río Manzanares, con concentraciones promedios de $10^{4}$, en las cercanías de la desembocadura.

Los resultados aquí reportados nos indican que no ha habido una solución a la problemática de la contaminación fecal del ecosistema. Al contrario, el aumento de las poblaciones en las riberas del manzanares está ocasionando un mayor desequilibrio de las condiciones ambientales.

\section{DETERGENTES}

La evolución de los detergentes a lo largo del Manzanares se presenta en la figura 11. Durante todo el trayecto las concentraciones de estos elementos se encontraron por debajo de los límites establecidos para las aguas del tipo 4. Se apreció una ligera disminución de las concentraciones en el lugar de confluencia de los ríos Guasdua y Cedeño con el Manzanares. Las concentraciones se incrementan hacia el sector de la desembocadura del río, donde las concentraciones superaron los valores límites establecidos por la normativa venezolana. 


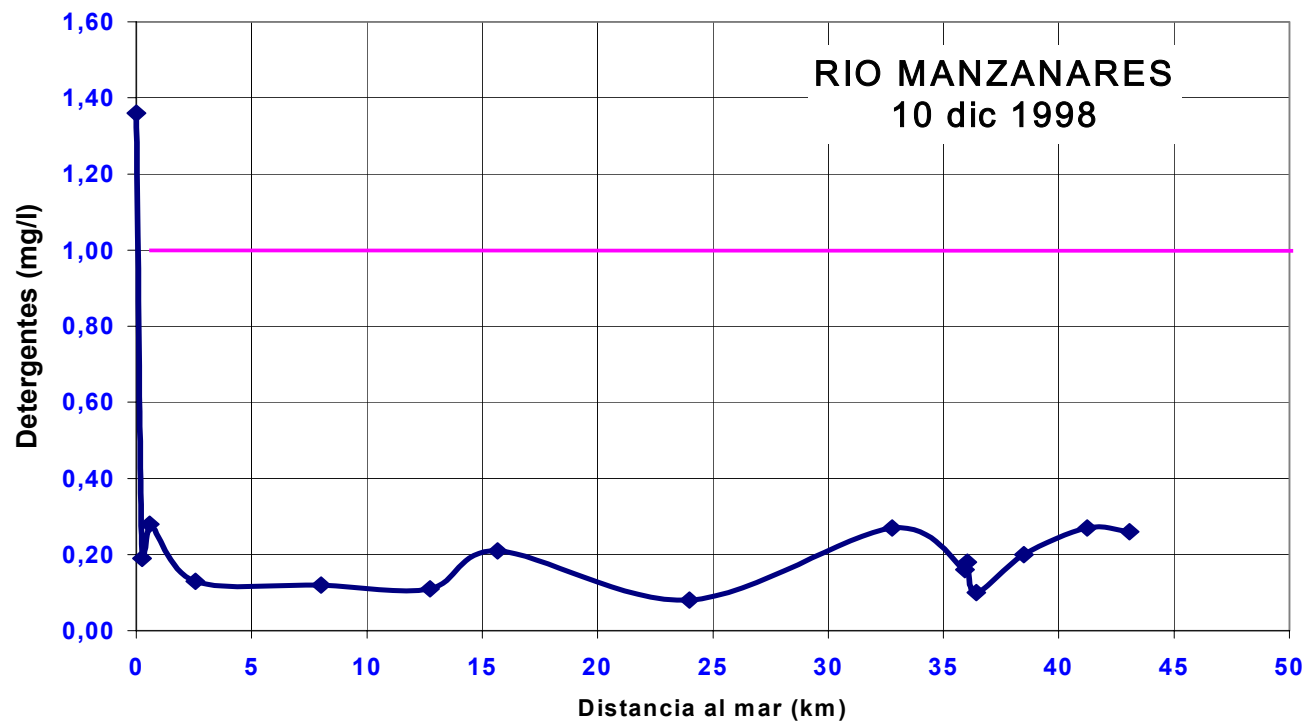

Fig. 11.- Variación longitudinal de los detergentes en el Río Manzanares, diciembre de 1999. La línea rosada indica el valor límite establecido para este tipo de aguas (Agua tipo 4: aguas destinadas al contacto humano parcial y/o total)

\section{ACEITES Y GRASAS}

Las concentraciones de aceites y grasas se mantuvieron por debajo de los límites establecidos en la normativa venezolana vigente. Sin embargo, se pudo apreciar el aporte de estos compuestos por intermedio de los ríos Guasdua, Quebrada Seca y San Juan. El incremento de las concentraciones en este último sector es ocasionado por el vertido de estos compuestos al curso de agua, como consecuencia del lavado de vehículos, cambios de aceites y talleres mecánicos que se encuentran en el sector. Las concentraciones aumentan abruptamente hacia el tramo final del río, para sobrepasar los límites establecidos en la Legislación vigente, para las aguas del tipo 4 . El incremento de las concentraciones en el tramo final del río es consecuencia de la diversidad de desechos domésticos e industriales que son vertidos al Manzanares, en esta región. (Ver fig. 12) 


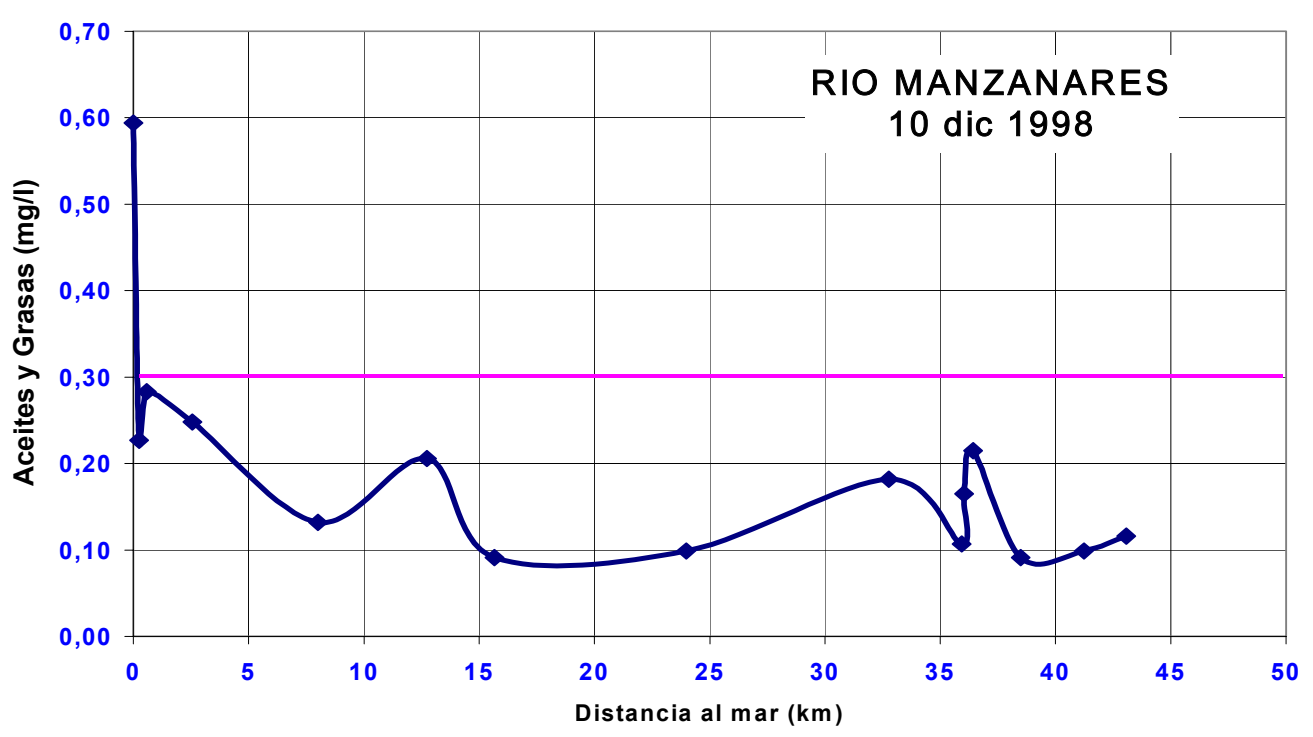

Fig. 12.- Variación longitudinal de aceites y grasas en el Río Manzanares, diciembre de 1999. La línea rosada indica el valor límite establecido para este tipo de aguas (Agua tipo 4: aguas destinadas al contacto humano parcial y/o total)

\section{SOLIDOS SUSPENDIDOS}

Las variaciones longitudinales de las concentraciones de sólidos suspendidos en el Manzanares fueron variables (fig. 13). Los valores estuvieron comprendidos entre $2 \mathrm{mg} / \mathrm{l}$ y $50 \mathrm{mg} / \mathrm{l}$. Las más elevadas concentraciones se detectaron en el sector de Quebrada Seca, donde se apreció un aporte importante de estos elementos. La concentraciones disminuyen posteriormente, por la mezcla de las aguas, para alcanzar nuevos máximos a la altura de Barrancas y Puerto de La Madera. Estos incrementos de las concentraciones de sólidos en suspensión están asociados a las extracciones de arena que se llevan a cabo a lo largo del río, afectando de manera importante grandes sectores del ecosistema.

En el tramo final del Manzanares se aprecia el incremento de las concentraciones por los aportes realizados en el sector de Cumaná. 


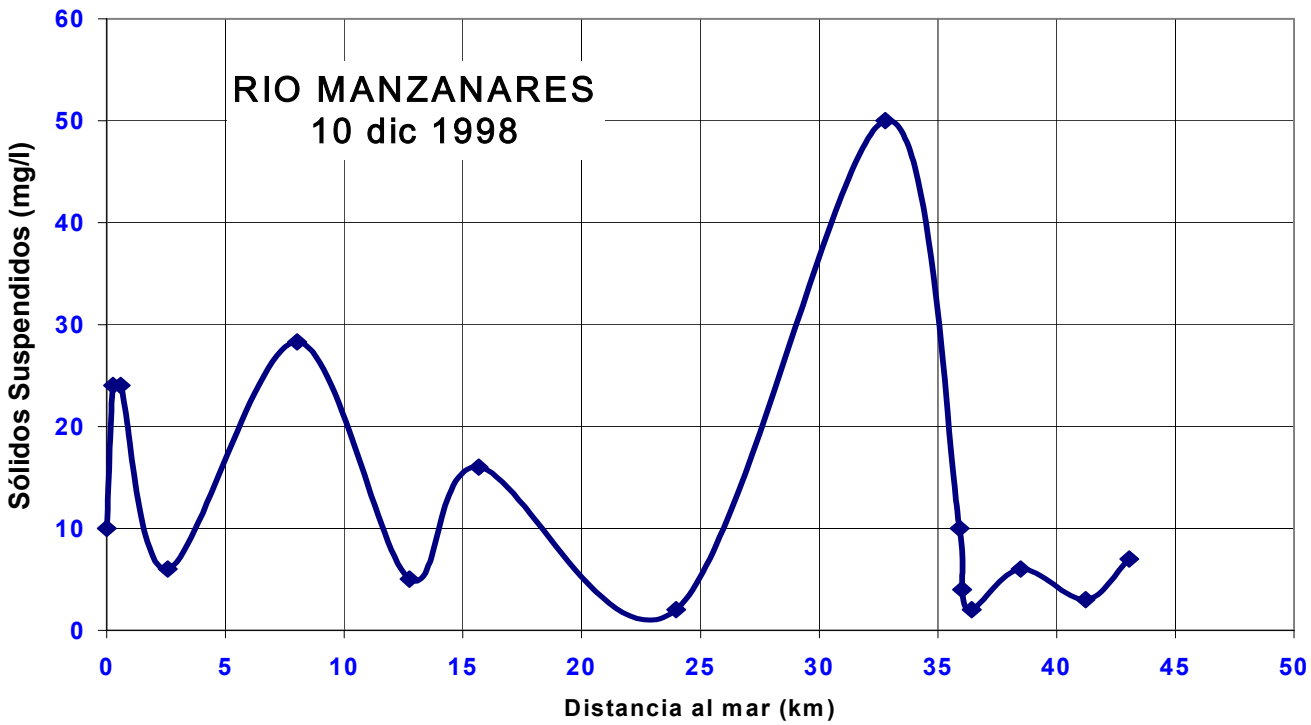

Fig. 13.- Variación longitudinal de los sólidos suspendidos en el Río Manzanares, diciembre de 1999.

\section{FENOLES}

Las concentraciones longitudinales de fenoles fueron variables durante todo el trayecto examinado (fig.14). Las concentraciones variaron entre no detectadas y $0,43 \mathrm{mg} / \mathrm{l}$. En gran parte del trayecto examinado, las concentraciones de fenoles excedieron los valores límites establecidos por la Legislación venezolana, para las aguas del tipo 4. Las elevadas concentraciones de fenoles son arrastradas desde la Cuenca alta del ecosistema. La disminución de los valores que se apreció en las cercanías del kilómetro 36, son consecuencia de la dilución de las mismas por la mezcla del Manzanares con el Guasdua. Similarmente, se aprecia disminuciones de las concentraciones en las intersecciones de los ríos Cedeño y San Juan. Las concentraciones disminuyen hacia el tramo final del ecosistema, apreciándose pequeños aportes a nivel de la ciudad de Cumaná. 


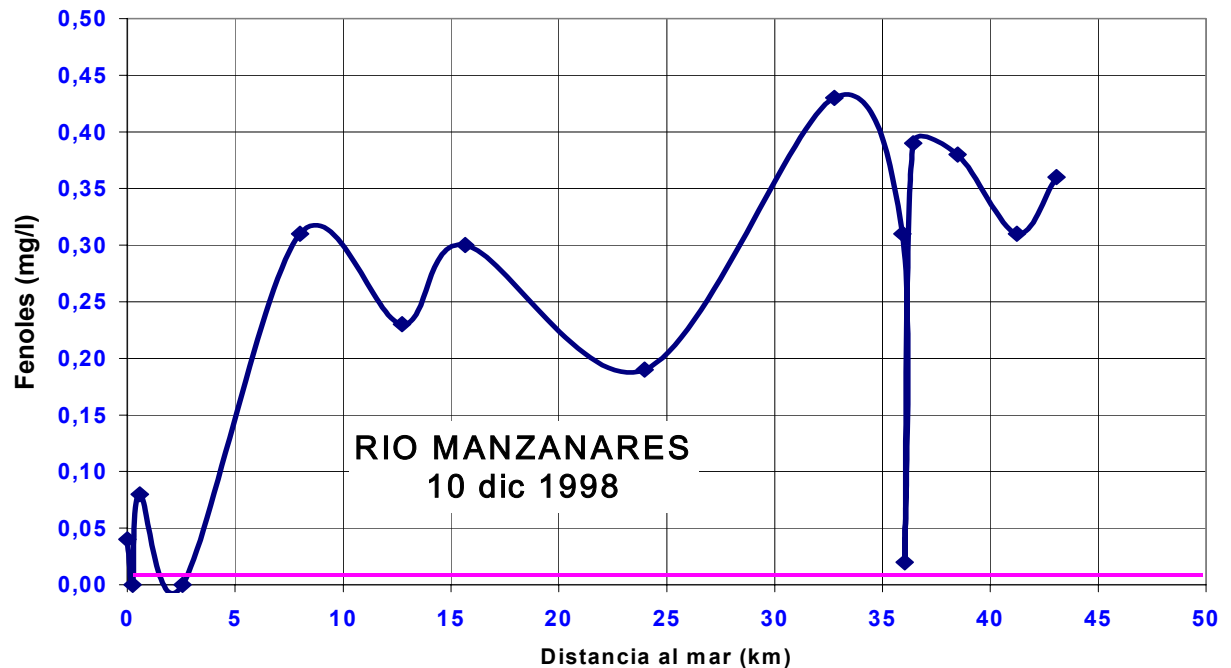

Fig. 14.- La línea rosada indica los valores límites establecidos para las aguas de tipo 4, Aguas destinadas a balnearios, deportes acuáticos y pesca.

\section{COBRE}

Las concentraciones de cobre estuvieron comprendidas entre no detectado y $18 \mu \mathrm{g} / \mathrm{l}$ (fig. 15). Las concentraciones de cobre se incrementan abruptamente en las cercanías del kilómetro 36, como consecuencia del aporte de Quebrada Seca. Estas concentraciones se mantienen elevadas, para descender posteriormente en el sector de Barrancas. A partir de este punto, los valores incrementar para alcanzar un nuevo máximo en el sector del Puente Raúl Leoni, ubicado en la ciudad de Cumaná. Este incremento de las concentraciones en este sector nos está señalando un aporte importante de estos elementos, posiblemente asociado a las viviendas insalubres ubicadas en la región. Posteriormente las concentraciones disminuyen como consecuencia de la mezcla de las aguas del río y las aguas marinas. Es de resaltar que la Legislación venezolana establece concentraciones de metales trazas, a nivel de no detectados para las aguas de clasificación de tipo 4. 


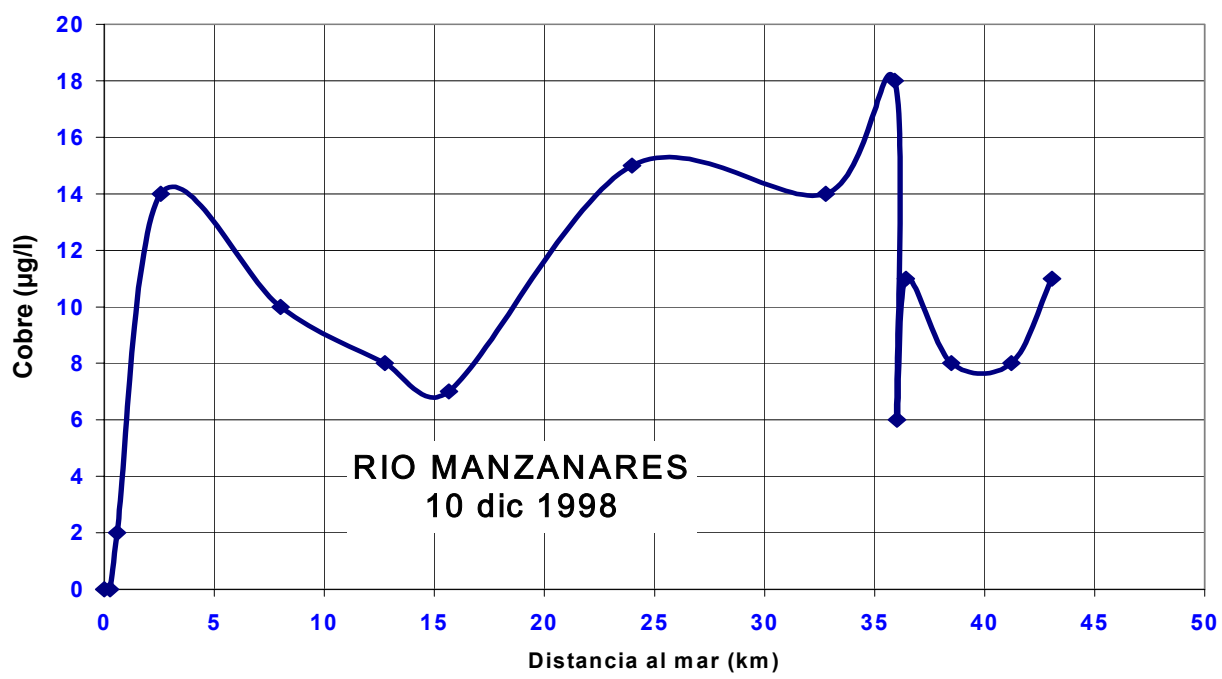

Fig. 15.- Variación longitudinal de la concentración del cobre (Cu) en el río Manzanares, diciembre de 1998.

\section{CINC}

Las concentraciones longitudinales del cinc total estuvieron comprendidas entre $7 \mu \mathrm{g} / \mathrm{y}$ $59 \mu g / l$ (fig. 16). Las concentraciones se mantuvieron homogéneas entre los 45 y 10 kilómetros, a pesar de que se pudo detectar un ligero aporte de este elemento por el río Cedeño. Las concentraciones aumentaron abruptamente en el puente Raúl Leoni, para luego disminuir hacia la desembocadura, a la entrada del Golfo de Cariaco. Este incremento de las concentraciones está relacionado directamente con el aumento de los valores de cobre, sugiriendo un mismo origen para ambos elementos.

\section{CROMO}

Entre los kilómetros 3 y 45 no se detectó la presencia de cromo en las aguas superficiales del río Manzanares (fig. 17). Las concentraciones se incrementan hacia la desembocadura del río, 
alcanzando valores de $28 \mu \mathrm{g} / \mathrm{l}$. Esta distribución pone en evidencia la existencia de un aporte de estos elementos, en este tramo del ecosistema.

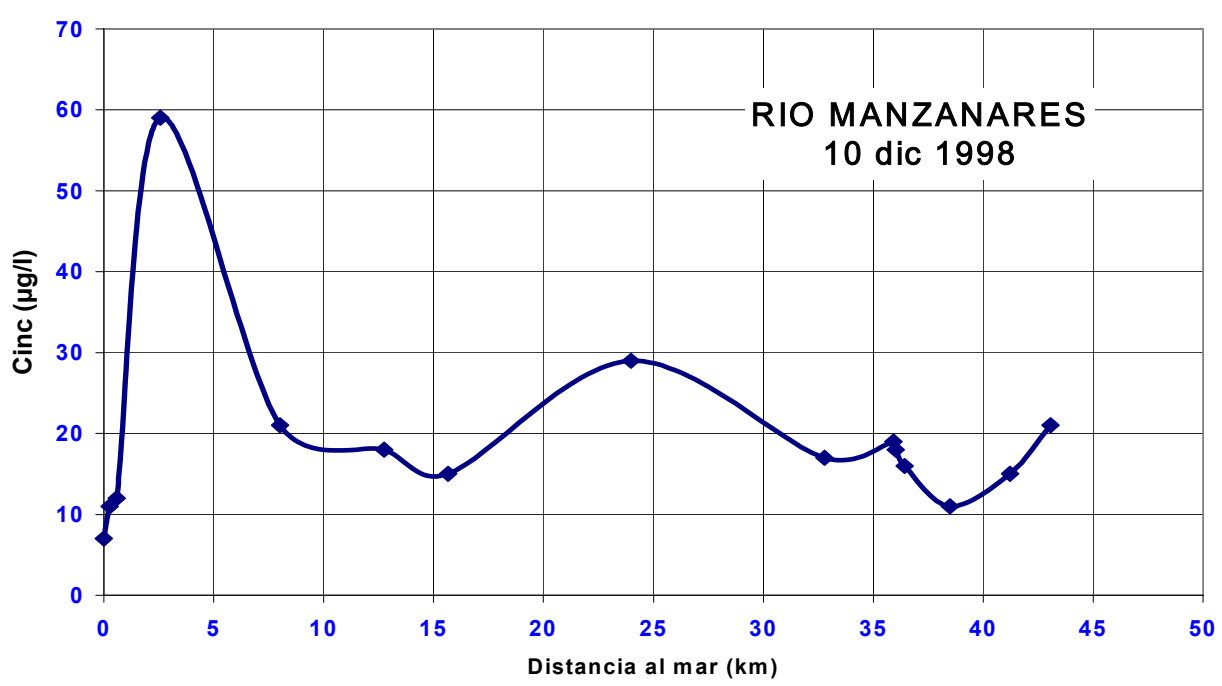

Fig. 16.- Variación longitudinal de la concentración del Cinc total en el río Manzanares, diciembre de 1998.

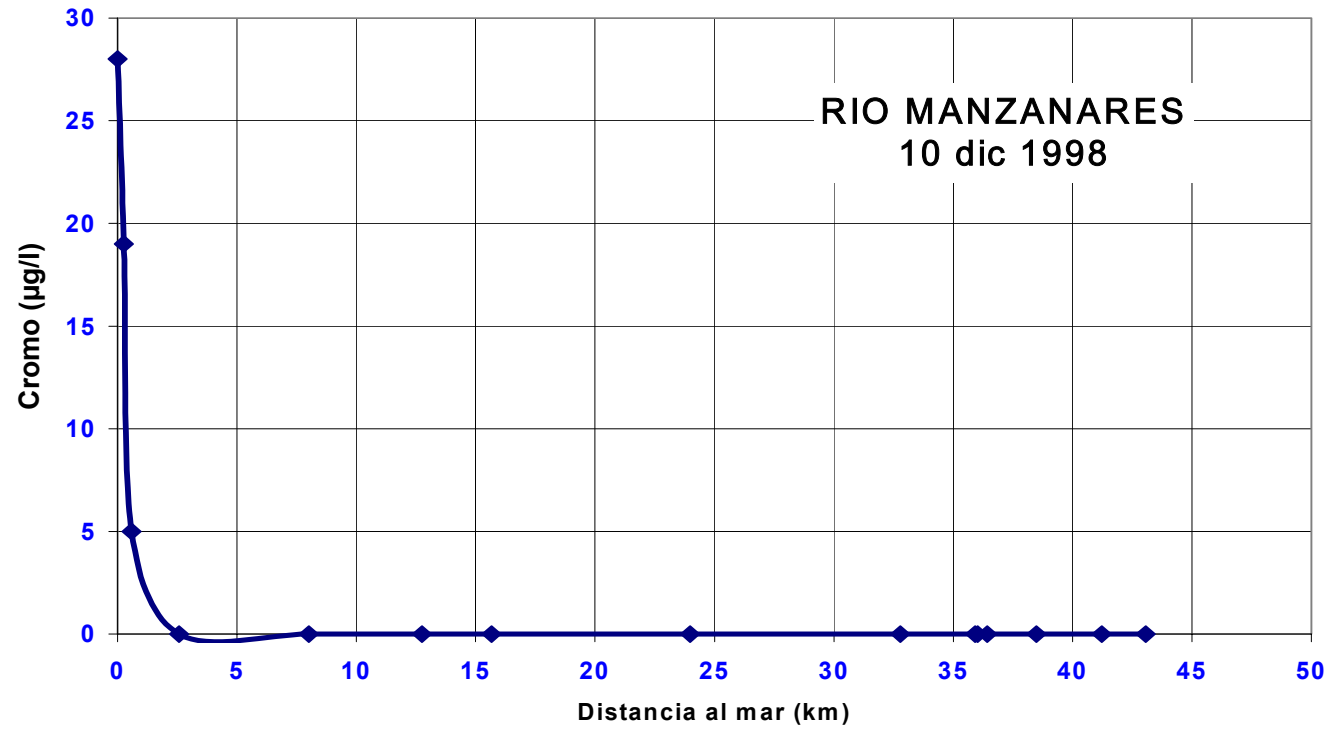

Fig. 17.- Variación longitudinal de la concentración del Cromo total en el río Manzanares, diciembre de 1998. 


\section{NIQUEL}

La distribución del níquel total fue bastante irregular, y caracterizada por aportes puntuales de este elemento (fig. 18). Estos aportes ocurrieron en las intersecciones de los ríos Guasdua, Quebrada Seca y en el sector de Puerto de La Madera. Los valores máximos registrados fueron de $4 \mu \mathrm{g} / \mathrm{l}$.

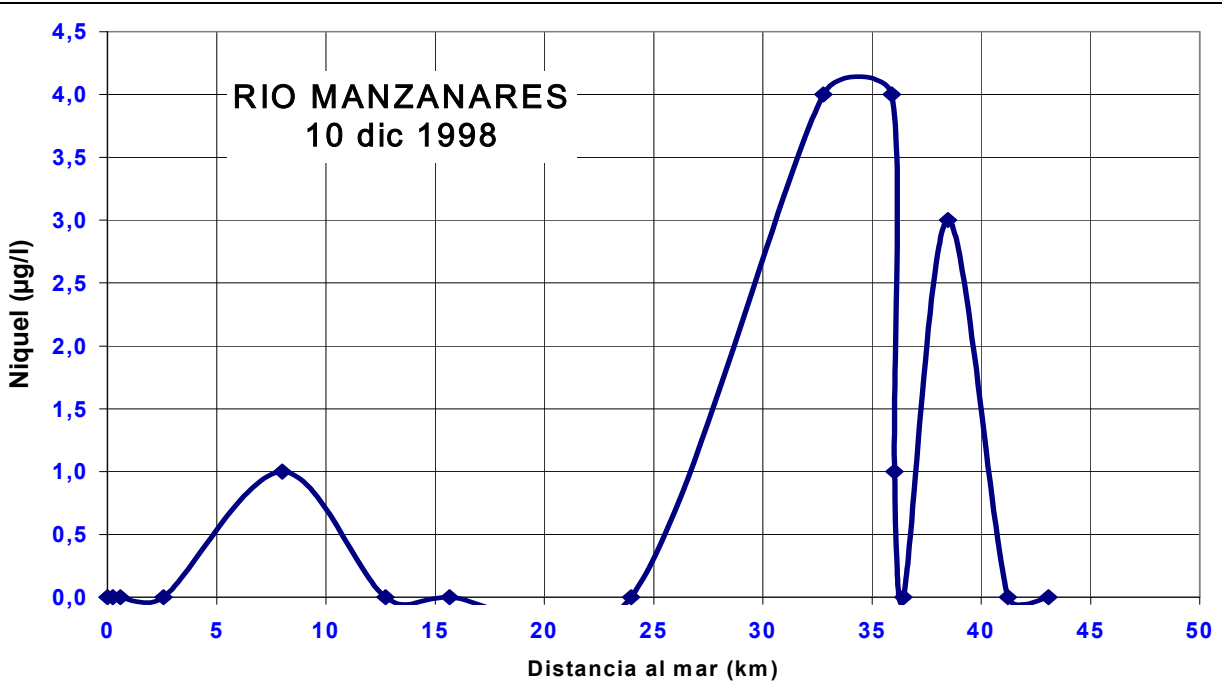

Fig. 18.- Variación longitudinal de la concentración del Niquel total en el río Manzanares, diciembre de 1998

\section{HIERRO}

Las concentraciones de hierro se incrementaron a medida que nos dirigimos hacia la desembocadura del Manzanares (fig. 19). Las concentraciones oscilaron entre no detectadas, en la zona marina, hasta $744 \mu \mathrm{g} / \mathrm{l}$. Se pudo apreciar un aporte de este elemento por intermedio de la Quebrada Seca, como a nivel de Puerto de La Madera. En su tránsito por la ciudad de Cumaná se apreciaron aportes importantes de este elemento.

\section{MANGANESO}

La evolución del manganeso fue bastante similar a la seguida por el hierro (fig. 20 y 19). Las concentraciones estuvieron comprendidas entre $3 \mu \mathrm{g} / \mathrm{l}$ y $58 \mu \mathrm{g} / \mathrm{l}$, registrándose los más elevados valores al paso del río por la ciudad de Cumaná. Hacia la parte alta del ecosistema se detectaron aportes de este elemento por la Quebrada Seca y por el río Cedeño.

León Luna (1995) señala que las concentraciones de la mayoría de los metales, en la cuenca baja del Manzanares, están regidas por el ciclo hidrológico del río. Marques (1997) puso en evidencia que el mayor porcentaje de estos elementos llegan al ecosistema asociados al material en suspensión, incrementándose las concentraciones durante los períodos de máximo caudal del río. 


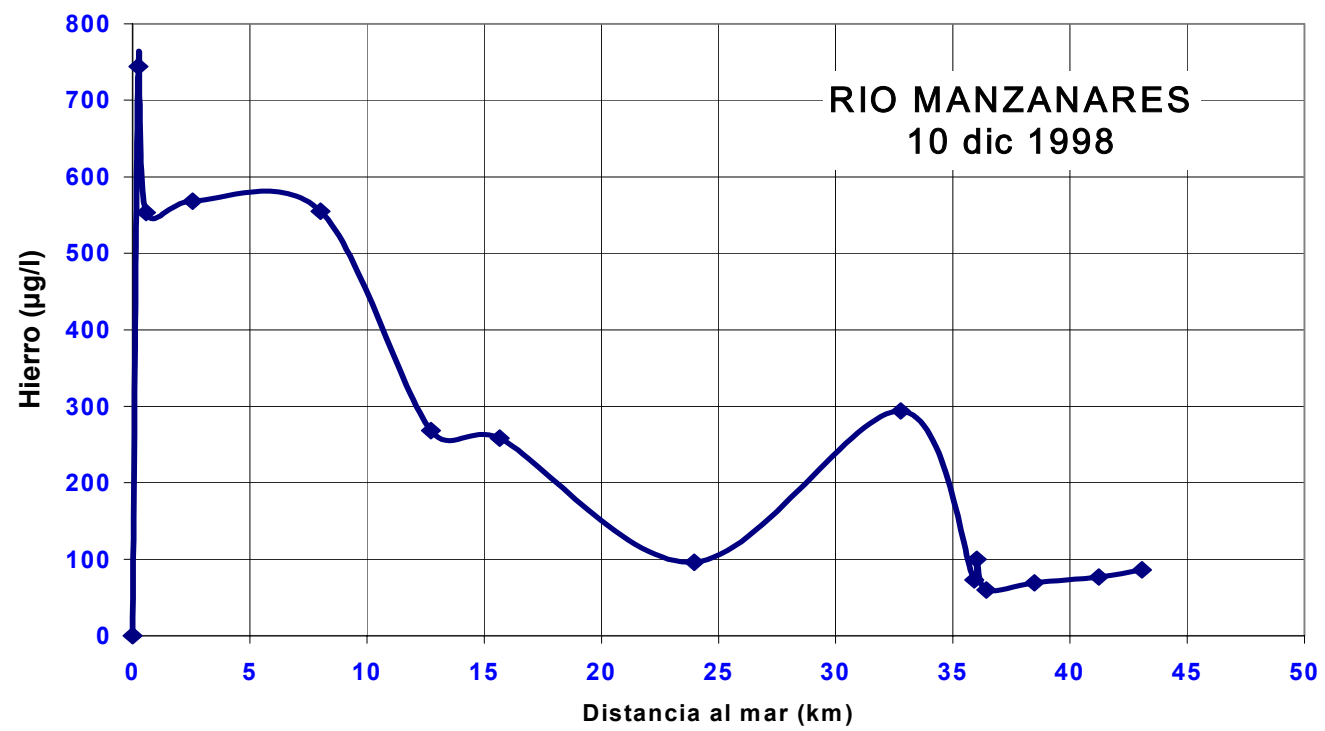

Fig. 19.- Variación longitudinal de la concentración del Hierro total en el río Manzanares, diciembre de 1998

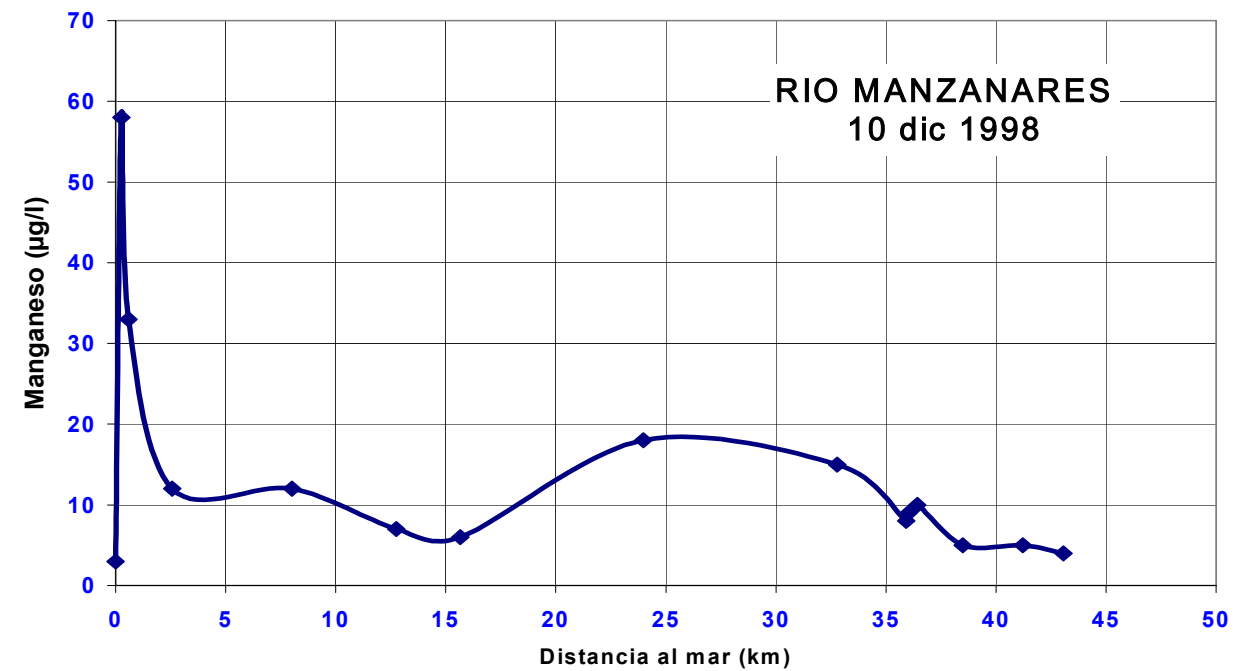

Fig. 20.- Variación longitudinal de la concentración del Manganeso (Mg) en el río Manzanares, diciembre de 1998. 


\section{CONCLUSIONES Y RECOMENDACIONES}

Todo cuerpo de agua posee una inherente capacidad limitada para asimilar compuestos contaminantes, lo cual define su capacidad de autopurificación, la cual va a depender del carácter dinámico del mismo. Entre los factores más importantes que regulan el potencial de un ecosistema para asimilar contaminantes están el gasto del río, el tiempo de residencia de las aguas, las variaciones de temperatura y la calidad de los sedimentos.

Para el Manzanares. durante los meses de sequía, la fuerte disminución del gasto del río menoscaba su capacidad de autopurificación. Esto lo confirman los bajos niveles de oxígeno disuelto encontrados, los cuales a su vez se originan como resultado de la descomposición de la materia orgánica - tanto la arrastrada por el ecosistema, como la vertida de indiscriminadamente por el hombre-.

En términos sanitarios los resultados aquí reportados apuntalan al Río Manzanares como un curso de agua de alto reisgo. Peligro que se extiende a las costas cumanesas, que acojen las sus descargas contaminadas, y hasta las áreas turíticas de Mochima. Esta última, según observaciones realizadas por el IOV-UDO durante la época lluviosa. Considerando los múltiples usos a que están sometidas las aguas del Manzanares, el nivel actual de contaminación amérita su declaración de no apto para el uso turístico y recreacional.

En relación a estudios previos, es motivo de preocupación la persistencia de altos niveles de coliformes fecales (indicadores de contaminación fecal). Pareciera, que este hecho ha sido ignorado insistentemente por las autoridades sanitarias y del ambiente regionales en detrimento de la salud de la población rural que se asienta en sus márgenes y de los turístas

Se hace necesario la reactivación y el control de funcionamiento de las lagunas de oxidación existentes entre la ciudad de Cumaná y Cumanacoa, muchas de las cuales ya son incapaces de poder tratar los volúmenes elevados de desechos. 
El control del aporte de desechos, tanto de origen industrial, como doméstico debe ser emprendido inmediatamente en la cuenca baja del ecosistema. Es inconcebible como aun, empresas como AVECAISA, vierten los desechos crudos de sus procesos, sin ningún tipo de tratamiento, a la vista de todas las autoridades ambientales, sanitarias y gubernamentales. La fuente de contaminación, en la que han sido convertidos los mercados municipal y de pescadores, deben ser inmediatamente eliminadas, mediante un sistema de recolección adecuado de los desechos.
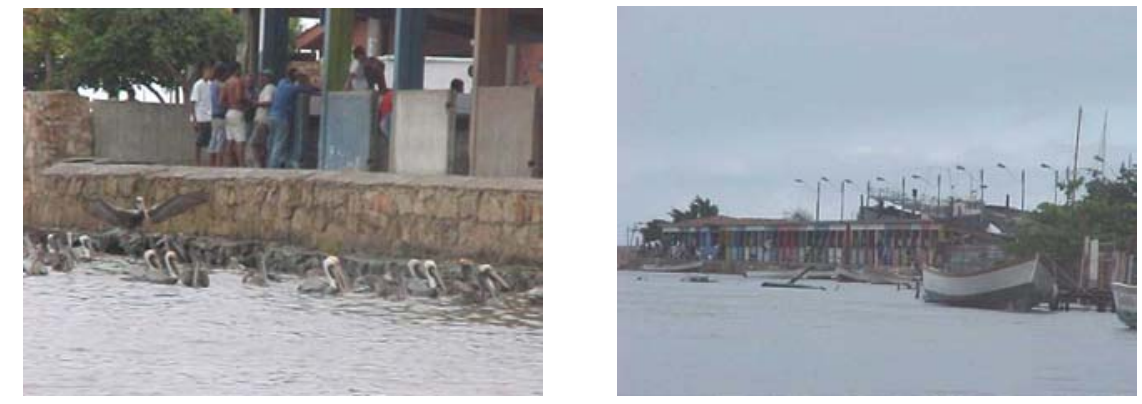

Foto 1.- Desembocadura del Río Orinoco. Ventas públicas de pescado fresco.
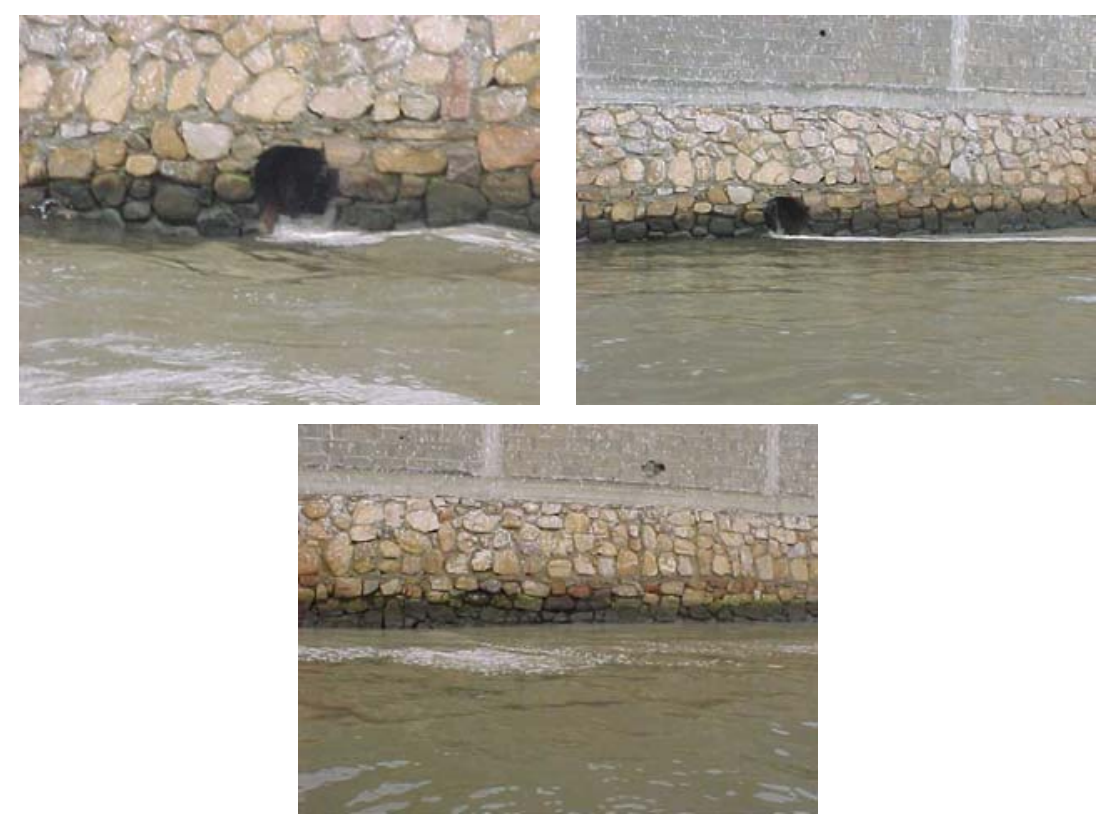

Foto 2.- Descargas de los efluentes de las procesadoras de pescados asentadas en la desembocadura del río. 

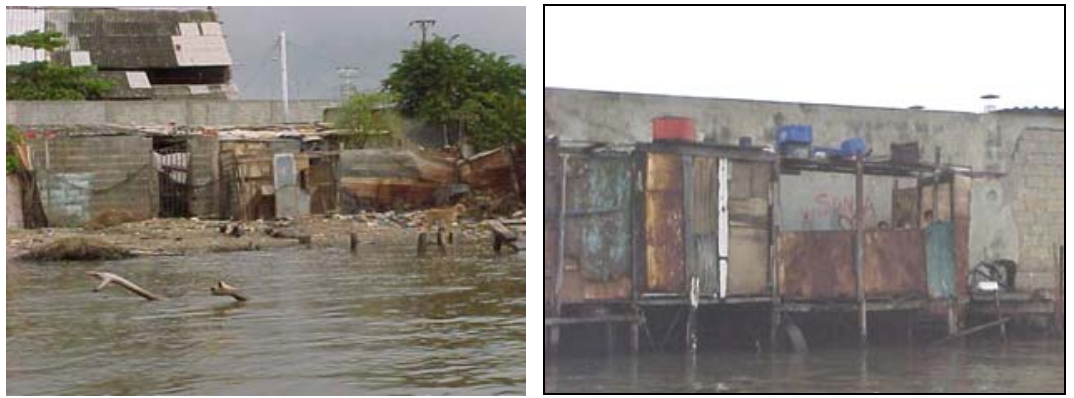

Foto 3.- Soluciones habitacionales de los pobladores que se asientan en las márgenes del río, hacia el final de la desembocadura.

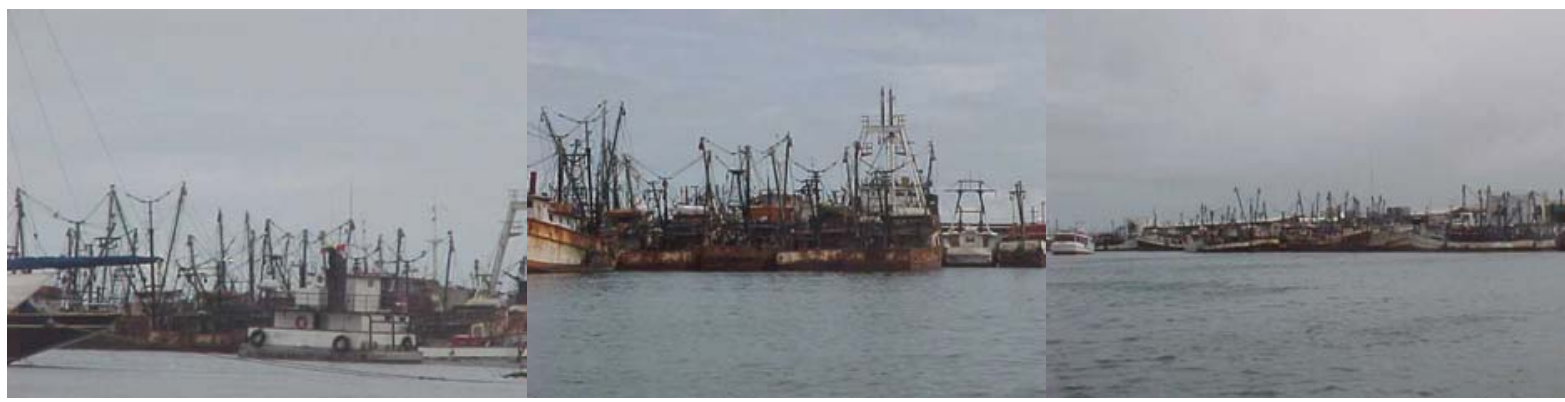

Foto 4.- Flota de embarcaciones del tipo arrastradoras, tienen su sede en el sector Puerto Sucre y el muelle conocido como Las Lonjas Pesqueras

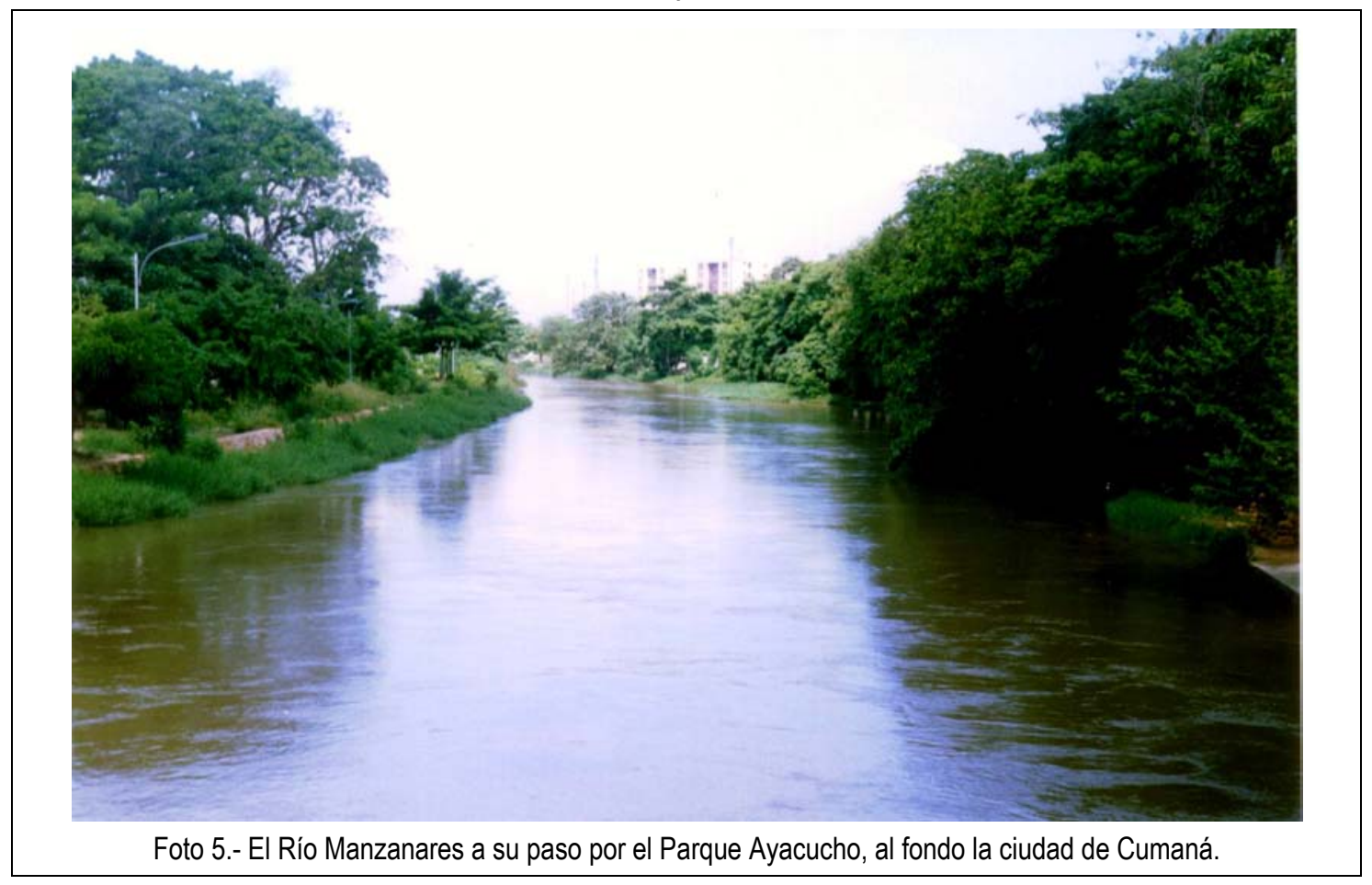


